\title{
Sedation choices and mortality: a well-defined tandem?
}

\author{
Chuan Jiang ${ }^{1}(\mathbb{D}) \cdot$ Antonio M. Esquinas $^{2} \cdot{\text { Bushra } \text { Mina }^{3}}^{3}$
}

Received: 16 July 2016 / Accepted: 20 July 2016 / Published online: 28 July 2016

(C) Japanese Society of Anesthesiologists 2016

Keywords Sedation · Propofol · Benzodiazepines · Mechanical ventilation

To the Editor:

Hayashida et al. [1] reports significantly decreased days of intubation and mortality in mechanically ventilated patients sedated with propofol compared to benzodiazepines. A recent meta-analysis by Fraser and colleagues [2] also compared these sedation strategies and demonstrated similar results. However, the latter did not demonstrate a significant difference in mortality.

For further discussion, we consider the work of Shehabi and colleagues [3], which demonstrated that early sedation depth independently predicts increased 180-day mortality in mechanically ventilated ICU patients. Propofol and midazolam were used at the same frequency during the first $48 \mathrm{~h}$, the critical early period. Although the dosage of sedatives cannot be interpolated from the data, it is interesting to consider the role of the choice of sedation in the sedation depth.

This comment refers to the article available at doi:10.1007/s00540-016-2196-z.

Chuan Jiang

CJiang@northwell.edu

1 Division of Nephrology, Department of Medicine, Northwell Health System, Lenox Hill Hospital, New York, NY 10075, USA

2 Intensive Care Unit, Hospital Morales Meseguer, Murcia, Spain

3 NSLIJ, Lenox Hill Hospital, New York, NY, USA
The data by Hayashida and colleagues offer valuable new clinical insight into ICU sedation strategies by suggesting that the choice of sedative may influence patient outcomes. However, it is not apparent if this effect is independent of the depth of sedation. Nevertheless, we eagerly await these author's future study results.

\section{Compliance with ethical standards}

Conflict of interest None declared.

\section{References}

1. Hayashida, K, Umegaki T, Ikai H, Murakami G, Nishimura M, Imanaka Y. The relationship between sedative drug utilization and outcomes in critically ill patients undergoing mechanical ventilation. J Anesth. 2016 (Epub ahead of print).

2. Fraser GL, Devlin JW, Worby CP, Alhazzani W, Barr J, Dasta JF, Kres JP, Davidson JE, Spencer FA. Benzodiazepine versus nonbenzodiazepine-based sedation for mechanically ventilated, critically ill adults: a systematic review and meta-analysis of randomized trials. Crit Care Med. 2013;41:S30-8.

3. Shehabi Y, Bellomo R, Reader MC, Bailey M, Bass F, Howe B, McArthur C, Seppelt IM, Webb S, Weisbrodt L. Early intensive care sedation predicts long-term mortality in ventilated critically ill patients. Am J Respir Crit Care Med. 2012;186(8):724-31. 